\title{
The Impact of Written vs. Oral Corrective Feedback on Omani Part-time vs. Full-time College Students' Accurate Use and Retention of the Passive Voice
}

\author{
Farhad Tayebipour \\ Majan University College, Oman
}

\begin{abstract}
The present study was an attempt to discover the effects of explicit written vs. explicit oral corrective feedback on Omani part-time vs. full-time College students' accurate use and retention of the passive voice. The participants consisted of the students of six intact classes, i. e. three part-time and three fulltime, who took an Oxford Quick Placement Test (OQPT) as a general proficiency test. Following the proficiency test, the participants took three similar, but not identical, tests on the target structure as pretest, posttest and delayed posttest. In response to the errors made in the pretest, the experimental groups received explicit written and explicit oral corrective feedback in their treatment phase whereas the control groups did not receive such explicit written or explicit oral feedback. The accuracy of the use and retention of the passive voice was measured by a posttest and a delayed posttest. The results indicated a significant difference between the pretest performance of the experimental groups and their performance in the posttest and the delayed posttest. Similarly, the results showed a significant difference between the performance of the experimental groups and that of the control groups in the sense that the experimental groups outperformed the control groups. In addition, there was a significant difference between the performance of the part-time students and that of the full-time students in that the part-time students outperformed the full-time students. Finally, there was no significant difference between the experimental groups' performance on the posttest and their performance on the delayed posttest.
\end{abstract}

Index Terms - corrective feedback, explicit written, explicit oral, part-time, full-time

\section{INTRODUCTION}

Being skeptical about the effectiveness of corrective feedback (CF) in second language (L2) development (e.g. Krashen, 1982, Truscott, 1996, 1999) has sparked a good number of CF research in the last three decades or so (e.g. Doughty and Verela, 1998; Mackey, 1999; Ashwell, 2000; Chandler, 2003; Hattie and Timperley, 2007; Ferris, 1999, 2003; 2008; Bitchener and Knoch, 2008, 2009; Sheen 2007, 2010; Ellis, 2010, Lyster, Saito, and Sato, 2013; Vahdani Sanavi and Nemati, 2014; Rassaei 2015, 2017, to name but a few). With a robust literature, CF is now said to be "not only beneficial but... necessary for moving learners forward in their L2 development [due to playing] pivotal role in the...scaffolding that teachers need to provide ...learners..." (Lyster, Saito and Sato, 2013, p.1 and p. 9).

However, the question as to which types/modes of CF play 'pivotal role', and are more effective in the development of L2 writing is still a matter of debate. In this respect, some researchers, such as Hyland and Hyland (2006, p.83), criticize feedback research for not being, "unequivocally positive about its role in the development of L2 writing." According to Hyland and Hyland (2006) issues related to feedback have not been sufficiently investigated by the researchers. Others, such as Ellis (2009), address unresolved issues such as the role of CF in L2 development, the type of errors CF research should address, and the most effective CF strategy.

Although among the issues referred to by Ellis (2009), one, i.e. the most effective CF strategy, or as Ferris (2008) calls it the 'mode of delivery', seems to have been addressed more frequently (e.g., Lochtman, 2002; Bitchener and Knoch, 2008; Nassaji, 2009; Lopez and Manchon, 2010; Erlam, Ellis and Batstone, 2013, Rassaie, 2013, 2017; Lyster, Saito, and Sato, 2013; Lyster and Saito, 2010; Yang and Lyster, 2010, to name but a few), the problem is that there is still no unequivocal yes/no answer to the 'mode of delivery' question as it is not yet clear which structures are more amenable to which CF strategies. That is possibly why CF research has been described as lacking 'ecological validity'. (Storch, 2010) According to Storch (2010, p.43) "Studies which provide feedback on one type of error and only on one piece of writing and in controlled environments are unlikely to be relevant to language teachers because they do not reflect real classroom conditions." To address the "ecological validity' issue and inconclusive nature of CF research, this study was conducted to investigate the impact of two types of corrective feedback, i.e. explicit written vs. explicit oral CF on Omani full-time and part-time College students' accurate use and retention of the passive voice.

\section{LITERATURE REVIEW}


According to Ellis (2010), CF research is carried out for theoretical as well as practical reasons. Theoretically speaking, researchers following Chomsky (e.g. Krashen, 1982; Truscott, 1996, 1999), assign little role to CF on the grounds that L2 acquisition occurs as a result of positive evidence, hence no need to provide L2 learners with negative evidence whereas those working in cognitive-interactionist domain (e.g. Long, 1996) attribute some roles to CF on the assumption that negative evidence can raise leaners' awareness and help them bridge the gap between form and meaning when communicating. (Ellis, 2010) On the other hand, researchers working within Vygotsky's sociocultural theory of mind (e.g. Aljafreh and Lantolf; 1984, Nassaji and Swain; 2000) take a fine-tuned approach to feedback provision. The reason, in Ellis's (2010, p.336) word, is that "sociocultural theory rejects the view that a single type of CF is best for learning." From a practical perspective, novel ideas have been sought by CF researchers in that they have been keen to know how L2 learners may improve their L2 writing. In Ferris's view (1999, cited in Ellis 2010), the main concern of these researchers has been L2 learners' writing development.

To operationalize CF strategies, various classifications have been proposed by CF researchers. Lyster and Ranta (1997), for example, proposed six CF strategies: explicit, recast, clarification requests, metalinguistic feedback, elicitation and repetition. Ranta and Lyster (2007) modified Lystrer and Ranta's (1997) classification and put the six strategies under two broad categories: Reformulation and prompts. Reformulation included recasts and explicit correction while prompts included elicitation, metalinguistic clues, clarification requests and repetition.

Lyster and Saito (2010) amended Ranta and Lyster's (2007) taxonomy as a result of which the six strategies and the two broad categories were rearranged on an explicit/implicit scale. In the case of implicit reformulation, for example, one may conceive of conversational recasts, repetition and clarification requests while in the case of explicit reformulation, didactic recasts, and explicit correction with metalinguistic explanations can be conceived. Similarly, Ellis (2009) classified CF strategies into direct/indirect, focused/unfocused, electronic, meta-linguistic and reformulation strategies. In direct feedback, learners are provided with the correct forms while in indirect feedback, learners are given hints showing that there are some mistakes somewhere in their sentences hoping that learners will discover the correct forms themselves. According to Bitchener and Knoch (2008), direct feedback can have various forms:

Additional forms of direct feedback may include written meta-linguistic explanation (the provision of grammar rules and examples at the end of a student's script with a reference back to places in the text where the error has occurred) and/or oral meta-linguistic explanation (a mini-lesson where the rules and examples are presented, practised and discussed; one-on-one individual conferences between teacher and student or conferences between teacher and small groups of students).(p.1)

Direct feedback, in Sheen's (2010) study, included both oral and written feedback on an error along with some metalinguistic explanation. Oral feedback was operationalized as the "teacher's [oral] provision of the correct form following an error, together with metalinguistic information [while written feedback operationalized as] the provision of [written] metalinguistic explanation to justify the correct form when an error [was] made." (p.213)

The types of CF strategies mentioned above have been employed by teachers or researchers as oral or written CF. In the former, feedback is provided when L2 teachers/researchers have verbal communications with learners while in the latter, feedback is given when students' papers, scripts, and assignments are marked by teachers/researchers. In this respect, Ferris (2008) contends that some teachers prefer to provide written feedback on the same written text or in a separate sheet whereas some other teachers like better to sit with their students in a face-to-face manner and give them oral feedback with the intention that 'discussions of the student can be 'two-way' [and] clarification and explanation [can be] facilitated' (p.101).

\section{ORAL CORRECTIVE FEEDBACK}

With respect to oral $\mathrm{CF}$, there has been a tendency among CF researchers to compare recasts and explicit strategies. (e.g., Lochtman, 2002; Nassaji, 2009; Erlam, Ellis and Batstone, 2013, Rassaie, 2013, Lopez and Manchon, 2010; Bitchener, and Knoch, 2008; Lyster, Saito, and Sato, 2013; Lyster and Saito, 2010; Yang and Lyster, 2010, to name but a few). Lochtman (2002), for example, studied recast, explicit corrections, and teacher initiations and their impact on learners' uptake. It was initially hypothesized that explicit correction could be more salient than recast because it could make learners notice their errors without much effort and could lead to their higher rate of uptake. However, the results indicated a lower rate of learner uptake as a result of both recast and explicit corrections but a higher rate of uptake as a result of metalinguistic feedback and elicitations.

Similarly, Ellis, Lowen and Erlam (2006) studied recast and metalinguistic explanation and their impact on the acquisition of regular past tense morpheme $-e d$. The results indicated that explicit metalinguistic group outperformed the implicit one.

Likewise, Nassaji (2009) investigated the effects of recasts and elicitations on learning two linguistic items. To begin with, implicit and explicit forms of feedback were identified and their subsequent immediate effects were studied. Recast was overall found to be better than elicitation. However, learners performed better when they were provided with explicit rather than implicit feedback implying further that the more explicit the learners' feedback was, the better was their performance both in immediate as well as delayed posttest. 
In a similar vein, Rassaei (2013) compared the effects of recast with explicit correction on learners' acquisition of definite article 'the' and indefinite article 'a'. The results indicated that explicit correction was more effective since learners could become more aware of the corrective force of explicit feedback compared to recast. According to Rassaei (2013), "learners who received explicit correction outperformed those who received recasts because the explicit correction group could more easily notice the gap or perceive the interlocutors' corrective utterances as corrective feedback." (p.482)

Erlam, Ellis and Batstone (2013) compared the performance of two groups of learners in two similar writing tasks. The first group, called the 'explicit group', received explicit oral feedback based on cognitive-interactionist model while the second group, called the 'graduated group', received a 'tailored' type of feedback based on Vygotsky's (1978) Sociocultural model of feedback provision. The results indicated that participants in the 'graduated group' outperformed the 'explicit group' because of the degree of person-specific explicitness which was lacking in the 'explicit group'. In other words, the 'graduated group' feedback was more explicit than the 'explicit group' feedback in the sense that it was 'tailored' to and matched with each and every learner's specific level of attention, noticing and awareness.

Finally, Lyster et al (2013) reviewed various theoretical and practical aspects of oral CF such as frequency, preferences, laboratory vs. classroom studies and the targets studied. According to Lyster et al (2013, p. 20) "classroom studies of CF consistently confirm that oral CF is significantly more effective than no CF and also reveal a tendency for learners receiving prompts or explicit correction to demonstrate more gains on some measures than learners receiving recasts."

As the above studies may have indicated, in oral $\mathrm{CF}$, explicit correction is more effective because students may have opportunities of awareness raising when compared to implicit strategies such as recasts. Commenting on oral CF, Ellis (2010, p.173) also points out that "in classroom context, it would appear that explicit CF is more effective than implicit recasts."

\section{WRITTEN CORRECTIVE FEEDBACK}

As Bitchner and Knoch (2008) note, written CF studies have been a comparison between direct vs. indirect or between various types of indirect CF strategies. According to Bitchener and Knoch (2008), while Laland (1982) and Ferris and Helt (2000) report on the superiority of indirect CF, Chandler (2003) report on the superiority of direct CF. On the other hand, Robb, Ross and Shortreed, (1986) and Semke (1984) report no significant difference between the two types of $\mathrm{CF}$, i.e. direct vs. indirect.

As for the comparison of different types of indirect feedback, no difference has been reported. (eg. Ferris and Roberts, 2001; Ferris et al, 2000; Robert et al, 1986, cited in Bitchner and Knoch, 2008, p.415). Although Bitchener and Knoch (2008) are critical of written CF studies on the grounds that they suffer from design limitations, the overall results indicate that explicit written CF has been more effective than implicit CF strategies. To explain the above-mentioned results, Ellis (2010, p.173), for example, maintains that such "studies have shown that focused error correction leads to gains in linguistic accuracy and that the more explicit the feedback is, the better the results."

Furthermore, Sheen (2007) studied the impacts of two types of written CF on the acquisition of articles. The groups were a direct-only explicit correction group, a direct metalinguistic correction group (more explicit CF), and a control group. The results showed that both experimental groups outperformed the control group on the immediate posttest. However, the direct metalinguistic group, i.e. the more explicit one, performed better than the direct-only correction group in the delayed posttests. The results showed that written CF which was focused on one linguistic item was more effective especially when it was supported by metalinguistic explanations.

Considering oral vs. written $\mathrm{CF}$, a number of studies have compared the effectiveness of the two types and/or modes of CF. For example, Bitchener and Knoch (2008) compared direct corrective feedback, written and oral meta-linguistic explanation; direct corrective feedback and written metalinguistic explanation; direct corrective feedback only; and no corrective feedback. The results indicated that learners who received written CF performed better than those who did not receive written $\mathrm{CF}$, including those who received oral $\mathrm{CF}$, and that they could retain the accuracy level for several weeks. Similarly, Bitchener and Knoch (2009) found that learners who received written CF outperformed the control group on all four post-tests on both functions.

Lopez and Manchon (2010) investigated the effects of two direct CF strategies, i.e. error correction and reformulation on noticing and uptake in the written output of a group of EFL learners. The results confirmed the positive effects of written CF with a clear advantage of error correction over reformulation as far as uptake was concerned.

Finally, Sheen (2010) compared the effectiveness of oral vs. written CF on learners' correct use of English articles. Five groups were compared: oral recast, oral metalinguistic, written direct correction, written direct metalinguistic and control. The results indicated that the three CF types, i.e. oral metalinguistic, written direct and written direct with metalinguistic explanations but not oral recasts were effective. The point was that the degree of CF explicitness did matter for the effectiveness of the three types of CF strategies.

As the above brief review might have indicated, the extent to which CF strategies (written or oral) have been explicit may explain the reason as to why they have been more effective. The point is that various types of explicit feedback have rarely been compared. As Sheen (2010, p.172) argues, "to date, the effects of oral and written CF have been investigated independently of each other, and no study has systematically examined the relative efficacy of oral and 
written CF." Likewise, Bitchener and Knoch (2008) complain that "less attention has been given to a comparison of different direct feedback options." (p.415)

Addressing the 'ecological validity' issue in CF research (Storch, 2010) on the one hand and Sheen's (2010) and Bitchener and Knoch's (2008) concerns regarding the lack of comparison between types of direct feedback, this study was conducted to probe the efficacy of two types of explicit feedback, i.e., explicit written vs. explicit oral CF on Omani full-time vs. part-time College students L2 writing development. To operationalize the present study, Lyster et al's (2013) classification of CF was adopted. According to Lyster et al (2013), CF can be reformulations or prompts and both can be explicit or implicit. In explicit reformulation, explicit correction plus some metalinguistic explanations are provided. This study is, therefore, an attempt to make a comparison between explicit written vs. explicit oral CF on Omani full-time vs. part-time College students' accurate use and retention of the passive voice.

\section{METHODOLOGY}

\section{A. Research Design}

Based on the convenience sampling, six intact classes took part in an Oxford Quick Placement Test (OQPT) as a general proficiency test. Following the test rubrics, those who scored low were selected as the sample of the study since no one was supposed to know the target structure in advance.

\section{B. Target Structure}

The passive voice was selected as the target structure because of three reasons: The first reason was to address Storch's (2010) 'ecological validity' issue because it was part and parcel of the participants' curriculum and their classroom context. Secondly, as part of the participants' learning outcome, the passive voice was expected to be learned and utilized by the students in their end of the semester writing assignment. Third, and following Storch (2010) argument against CF's narrow scope, a less researched (Algarawi, 2010) target structure was selected.

\section{Participants}

The participants consisted of six intact classes who had registered in ARWB (Academic Reading and Writing for Business) module in the first semester of the academic year 2017-2018. Three classes included full-time students who attended their morning classes from 9:00 to 11:00 AM twice a week. Three classes included part-time students who attended their evening classes from 5:00 to 8:30 PM. Both full-time and part-time students studied at the Faculty of Business Management (FoBM) pursuing different pathways. The mean age of the full-time and part-time students were 20. The participants in the six classes were mixed-gender. Therefore, gender was not controlled in the study.

\section{Research Questions}

RQ1. Do types/modes of corrective feedback (explicit written vs. explicit oral) and modes of teaching (part-time vs. full time) have any differential effects on Omani College students' accurate use of the passive voice?

RQ2. Do types/modes of corrective feedback (explicit written vs. explicit oral) and modes of teaching (part-time vs. full time) have any differential effects on Omani College students' retention of the passive voice?

\section{E. Data Collection}

Oxford Quick Placement Test (OQPT) was administered as a general proficiency test. Based on the test results and the rubrics of the test, and for homogeneity reasons, those who scored high, i.e., upper intermediate and intermediate, were excluded from the study. This means that from among 150 students who took the proficiency test at the initial stage, 50 students were eventually selected. 27 students were full-time and 23 students were part-time students. The selection process was influenced by two factors: high score and low attendance. The students who scored high in the proficiency test and the students who did not attend either the pretest, or the posttest or the delayed posttest were dropped from the analysis.

Having taken the general proficiency test, the participants took a test as the pretest which was on the passive voice. The pretest consisted of 20 multiple-choice recognition and production items on the passive voice including four tenses: simple present, simple past, simple future and present perfect. The reason why the four tenses were included was that they were all part and parcel of the teaching materials and none of them could be eliminated from the syllabus of instruction.

The multiple choice items consisted of one recognition item and four production items for each tense. The rationale behind having recognition items before the production ones was that recognition was thought to be instrumental to the more difficult stage of production. In the recognition items, participants had to differentiate between a passive and an active structure whereas in the production items, they had to change a given active voice into a passive voice following an example given or had to produce passive structures on their own.

The pretest papers in the experimental groups were collected, and marked by two markers: The researcher himself and one of the two colleagues already mentioned. Following the pretest, the students in the experimental groups were provided with relevant explicit written and explicit oral CF. In the case of explicit written CF, the students' erroneous sentences were corrected by the researcher and written metalinguistic explanations were provided at the end of their 
papers. To do so, the erroneous word or structure was underlined and explanations were given at the end of their question papers. For example,

Student's writing: The books is written by a well-known author.

Teacher's written explanations: The books are written by a well-known author. [Explanation: Please note that the books are plural so 'the books' should be followed by an appropriate plural auxiliary verb. In this particular case, 'are' rather than 'is' should have been used.]

In the case of explicit oral feedback, the participants' written sentences were read one by one by the researcher and oral metalinguistic explanations were given to each and every student in a face-to-face manner. The only difference between the two types/modes of feedback was that in the latter case, the feedback had to be vocalized and presented orally while in the former, it had to be written and presented in a written form.

Having provided the students with relevant written or oral feedback, the posttest was administered in the following session. The question items in the posttest were similar to the pretest items. The reason for having similar test items was to be consistent in terms of test construction and test administration. The posttest was marked by the researcher twice and an intrarater reliability of 0.99 was obtained. In addition, the same colleague who marked the pretest, marked the posttest and an interrater reliability index of 0.97 was obtained. One week after the posttest, the delayed posttest was given. The same markers marked the delayed posttest and a similar interrater reliability index of 0.97 was obtained.

\section{F. Data Analysis}

The data collected were analysed using SPSS software employing Two-way ANCOVA was employed. Two-way ANCOVA's assumptions such as normality of the data, reliability of instruments and homogeneity of variances were met. In addition, a selected sample of the students' end of semester writing assignments were analysed to find out if the participants were affected similarly or differently by the two explicit types of feedback.

\section{RESULTS}

With respect to Two-way ANCOVA's assumption, normality of the data was obtained as the absolute values of the ratios of Skewness and Kurtosis over their standard errors were all lower than 1.96. As for the reliability of the instruments, a KR-21 reliability was performed. Table 1 displays the KR-21 reliability indices for the proficiency test, the pretest, the posttest and the delayed posttest. The reliability indices for the four tests were $.88, .83, .98$ and .95 respectively.

TABLE 1.

DESCRIPTIVE STATISTICS AND KR-21 RELIABILITY INDICES

\begin{tabular}{llllllll}
\hline & $\mathrm{N}$ & Minimum & Maximum & Mean & Std. Deviation & Variance & KR-21 \\
\hline Proficiency & 50 & 3 & 30 & 18.04 & 6.960 & 48.447 & .88 \\
Pretest & 50 & 0 & 40 & 15.10 & 8.481 & .83 \\
Posttest & 50 & 5 & 90 & 33.40 & 26.696 & 71.929 & 712.694 \\
Delayed & 50 & 0 & 75 & 25.00 & 17.814 & .98 & 317.347 \\
\hline
\end{tabular}

Regarding homogeneity of variances was met because the results of the Levene's test $(F(5,44)=.890, p=.496)$ indicated that there were no significant differences between the groups' variances. (Table 2)

TABLE 2.

LEVENE'S TEST OF EQUALITY OF ERROR VARIANCES ON PROFICIENCY TEST

\begin{tabular}{llllll}
\hline & \multicolumn{2}{c}{ Levene Statistic } & df1 & df2 & Sig. \\
\hline \multirow{4}{*}{ Proficiency } & Based on Mean & .890 & 5 & 44 & .496 \\
& Based on Median & .562 & 5 & 44 & .729 \\
& $\begin{array}{l}\text { Based on Median and with adjusted } \\
\text { df }\end{array}$ & .562 & 5 & 32.098 & .728 \\
& Based on trimmed mean & .834 & 5 & 44 & .533 \\
\hline \multicolumn{2}{r}{ Note. The Levene's test based on median was reported } &
\end{tabular}

Note. The Levene's test based on median was reported

Based on the results displayed in Table $3,(\mathrm{~F}(2,44)=.264, \mathrm{p}=.769$, partial $\mu 2=.012$ representing a weak effect size $)$ it can be claimed that there were not any significant differences between the three groups' means on the proficiency test. Thus it can be claimed that they were homogenous in terms of their general language proficiency prior to the administration of the treatments.

TABLE 3.

TESTS OF BETWEEN-SUBJECTS EFFECTS; PROFICIENCY TEST BY TREATMENT BY MODES OF TEACHING

\begin{tabular}{lllllll}
\hline & Type III Sum of & df & Mean Square & F & Sig. & Partial Eta Squared \\
\hline Source & Squares & & & .264 & .769 & .012 \\
Mode & 25.207 & 2 & 12.604 & .616 & .437 & .014 \\
Treatment * Mode & 29.422 & 1 & 29.422 & 2.440 & .099 & .100 \\
Error & 233.260 & 2 & 116.630 & & \\
Total & 2103.175 & 44 & 47.799 & & \\
\hline
\end{tabular}


The results displayed in Table $3,(\mathrm{~F}(1,44)=.616, \mathrm{p}=.437$, partial $\mu 2=.014$ representing a weak effect size $)$ indicated that there was not any significant difference between the two modes of teachings' means. As shown in Table 4, the part time $(\mathrm{M}=17.12, \mathrm{SE}=1.45)$ and full time $(\mathrm{M}=18.66, \mathrm{SE}=1.33)$ groups had almost the same means on the proficiency test.

TABLE 4.

DESCRIPTIVE STATISTICS; PROFICIENCY TEST B Y MODES OF TEACHING

\begin{tabular}{|c|c|c|c|c|}
\hline \multirow[b]{2}{*}{ Mode } & \multirow{2}{*}{ Mean } & \multirow{2}{*}{ Std. Error } & \multicolumn{2}{|c|}{ 95\% Confidence Interval } \\
\hline & & & Lower Bound & Upper Bound \\
\hline Part Time & 17.122 & 1.452 & 14.196 & 20.047 \\
\hline Full Time & 18.667 & 1.331 & 15.985 & 21.348 \\
\hline
\end{tabular}

And finally, there was not any significant interaction between types of treatment and modes of teaching on the proficiency test $(\mathrm{F}(2,44)=2.44, \mathrm{p}=.099$, partial $\mu 2=.100$ representing a weak effect size) (Table 3). As displayed in Table 5, the full time mode of teaching had the highest means across all treatments, except for the oral group where the part time mode had a negligibly higher mean.

TABLE 5.

DESCRIPTIVE STATISTICS; PROFICIENCY TEST BY TREATMENTS BY MODES OF TEACHING

\begin{tabular}{llllll}
\hline \multirow{2}{*}{ Treatment } & Mode & \multirow{2}{*}{ Mean } & \multirow{2}{*}{ Std. Error } & \multicolumn{2}{l}{$95 \%$ Confidence Interval } \\
\cline { 5 - 6 } Control & Part Time & 13.286 & 2.613 & 8.019 & Upper Bound \\
& Full Time & 20.778 & 2.305 & 16.133 & 25.422 \\
\hline \multirow{2}{*}{ Oral } & Part Time & 18.857 & 2.613 & 13.591 & 24.124 \\
& Full Time & 18.778 & 2.305 & 14.133 & 23.422 \\
\hline \multirow{2}{*}{ Written } & Part Time & 19.222 & 2.305 & 14.578 & 23.867 \\
& Full Time & 16.444 & 2.305 & 11.800 & 21.089 \\
\hline
\end{tabular}

Testing the first research question

The first research question asked if the types of feedback, i.e. explicit written vs. explicit oral and the modes of teaching, i.e. part time vs. full time, had any differential effect on Omani students' accurate use of the passive voice in the posttest. A two-way ANCOVA was run to investigate the effects of types of treatment and modes of teaching on the performance of the participants on the posttest, while controlling for the possible effects of their entry knowledge on passive voice as measured through the pretest. Two-way ANCOVA's assumptions such as normality of the data, reliability of instruments, homogeneity of variances, linear relationship between the covariate (pretest) and (posttest) and homogeneity of regression slopes were met. The former two assumptions were reported earlier. As for homogeneity of variances, the groups enjoyed homogenous variances on the posttest after controlling for the effects of the pretest ( $\mathrm{F}$ $(5,44)=2.07, \mathrm{p}=.086)($ Table 6$)$

TABLE 6.

LEVENE'S TEST OF EQUALITY OF ERROR VARIANCES; POSTTEST BY TREATMENTS BY MODES OF TEACHING WITH PRETEST

\begin{tabular}{llll}
\hline F & df1 & df2 & Sig. \\
\hline 2.078 & 5 & 44 & .086 \\
\hline
\end{tabular}

The significant results of the linearity test (Table 7$),(\mathrm{F}(1,41)=20.48, \mathrm{p}=.000)$ rejected the assumption that there was not any linear relationship between the covariate and the dependent variable. Thus it can be claimed that there was a linear relationship between pretest and posttest.

TABLE 7.

TESTING LINEARITY OF RELATIONSHIP BETWEEN PRETEST AND POSTTEST OF ACCURATE USE OF PASSIVE VOICE

\begin{tabular}{|c|c|c|c|c|c|c|c|}
\hline & & & $\begin{array}{l}\text { Sum of } \\
\text { Squares }\end{array}$ & df & Mean Square & $\mathrm{F}$ & Sig. \\
\hline \multirow{5}{*}{ Posttest * Pretest } & \multirow{3}{*}{ Between Groups } & (Combined) & 14758.738 & 8 & 1844.842 & 3.751 & .002 \\
\hline & & Linearity & 10071.716 & 1 & 10071.716 & 20.480 & .000 \\
\hline & & Deviation from Linearity & 4687.022 & 7 & 669.575 & 1.362 & .247 \\
\hline & Within Groups & & 20163.262 & 41 & 491.787 & & \\
\hline & Total & & 34922.000 & 49 & & & \\
\hline
\end{tabular}

And finally; the non-significant three-way interaction between types of treatment, modes of teaching and covariate (F $(2,38)=2.73, p=.078$, Partial $\eta^{2}=.126$ representing a moderate effect size) indicated that the assumption of homogeneity of variances was met. 
TABLE 8.

TESTING HOMOGENEITY OF REGRESSION SLOPES

\begin{tabular}{lllllll}
\hline Source & Type III Sum of Squares & df & Mean Square & F & Sig. & Partial Eta Squared \\
\hline Treatment & 610.610 & 2 & 305.305 & 1.412 & .256 & .069 \\
Mode & 868.745 & 1 & 868.745 & 4.019 & .052 & .096 \\
Pretest & 683.824 & 1 & 683.824 & 3.163 & .083 & .077 \\
Treatment * Mode & 1585.805 & 2 & 792.903 & 3.668 & .035 & .162 \\
Treatment * Pretest & 43.688 & 2 & 21.844 & .101 & .904 & .005 \\
Mode * Pretest & 8.534 & 1 & 8.534 & .039 & .844 & .001 \\
Treatment * Mode * Pretest & 1181.834 & 2 & 590.917 & 2.733 & .078 & .126 \\
Error & 8214.715 & 38 & 216.177 & & & \\
Total & 90700.000 & 50 & & & & \\
\hline
\end{tabular}

A two-way ANCOVA was run to investigate the effects of types of treatment and modes of teaching on the performance of the participants on the posttest, while controlling for the possible effects of their entry knowledge on passive voice as measured through the pretest. Based on the results in Table 9, $(\mathrm{F}(2,43)=13.30, \mathrm{p}=.000$, partial $\mu 2$ $=.382$ representing a large effect size) it can be claimed that there were significant differences between the three groups' mean values on the posttest.

TABLE 9.

TESTS OF BETWEEN-SUBJECTS EFFECTS; POSTTEST BY TREATMENTS BY MODES OF TEACHING WITH PRETEST

\begin{tabular}{|c|c|c|c|c|c|c|}
\hline Source & Type III Sum of Squares & df & Mean Square & $\mathrm{F}$ & Sig. & Partial Eta Squared \\
\hline Pretest & 1998.176 & 1 & 1998.176 & 8.540 & .006 & .166 \\
\hline Treatment & 6225.399 & 2 & 3112.699 & 13.304 & .000 & .382 \\
\hline Mode & 5225.157 & 1 & 5225.157 & 22.333 & .000 & .342 \\
\hline Treatment $*$ Mode & 4191.391 & 2 & 2095.695 & 8.957 & .001 & .294 \\
\hline Error & 10060.554 & 43 & 233.966 & & & \\
\hline Total & 90700.000 & 50 & & & & \\
\hline
\end{tabular}

Table 10 displays the descriptive statistics for oral, written and control groups on the posttest after controlling for the effects of the pretest. The oral group $(M=44.06)$ had the highest mean value on the posttest, followed by the written $(M$ $=39.95)$ and the control $(\mathrm{M}=16.38)$ groups.

TABLE 10 .

DESCRIPTIVE STATISTICS; POSTTEST BY TREATMENTS WITH PRETEST

\begin{tabular}{lllll}
\hline \multirow{2}{*}{ Treatment } & \multirow{2}{*}{ Mean } & \multirow{2}{*}{ Std. Error } & \multicolumn{3}{l}{$95 \%$ Confidence Interval } \\
\cline { 3 - 5 } & & & Lower Bound & Upper Bound \\
\hline Control & $16.380^{\mathrm{a}}$ & 4.072 & 8.168 & 24.592 \\
Oral & $44.069^{\mathrm{a}}$ & 3.862 & 36.279 & 51.858 \\
Written & $39.958^{\mathrm{a}}$ & 3.709 & 32.479 & 47.438 \\
\hline
\end{tabular}

The results of the post-hoc comparison tests (Table 11) indicated that explicit written group $(\mathrm{M}=39.95)$ significantly outperformed the control group $(\mathrm{M}=16.38)$ on the posttest $(\mathrm{MD}=27.68, \mathrm{p}=.000)$; that explicit oral group $(\mathrm{M}=44.06)$ significantly outperformed the control group $(\mathrm{M}=16.38)$ on the posttest $(\mathrm{MD}=23.57, \mathrm{p}=.000)$; and that no significant difference was observed between explicit oral $(M=44.06)$ and explicit written $(M=39.95)$ groups' mean values on the posttest $(\mathrm{MD}=4.11, \mathrm{p}=.443)$.

TABLE 11.

PAIRWISE COMPARISONS: POSTTEST BY TREATMENTS WITH PRETEST

\begin{tabular}{|c|c|c|c|c|c|c|}
\hline \multirow[b]{2}{*}{ (I) Treatment } & \multirow[b]{2}{*}{ (J) Treatment } & \multirow{2}{*}{$\begin{array}{l}\text { Mean Difference } \\
(\mathrm{I}-\mathrm{J})\end{array}$} & \multirow{2}{*}{ Std. Error } & \multirow{2}{*}{ Sig. } & \multicolumn{2}{|c|}{ 95\% Confidence Interval for Difference } \\
\hline & & & & & Lower Bound & Upper Bound \\
\hline \multirow{2}{*}{ Oral } & Control & $27.689^{*}$ & 5.671 & .000 & 16.252 & 39.125 \\
\hline & Written & 4.110 & 5.314 & .443 & -6.606 & 14.827 \\
\hline Written & Control & $23.578^{*}$ & 5.712 & .000 & 12.060 & 35.097 \\
\hline
\end{tabular}

Finally, based on the results displayed in Table 9 above and Table 12 below, $(\mathrm{F}(1,44)=22.33, \mathrm{p}=.000$, partial $\mu 2$ $=.342$ representing a large effect size $)$, it can be claimed that the part time group $(\mathrm{M}=43.78)$ had a significantly higher mean than the full time group $(M=23.15)$ on the posttest.

TABLE 12.

DESCRIPTIVE STATISTICS; POSTTEST BY MODES OF TEACHING WITH PRETEST

\begin{tabular}{lllll}
\hline \multirow{2}{*}{ Mode } & \multirow{2}{*}{ Mean } & \multirow{2}{*}{ Std. Error } & \multicolumn{3}{l}{$95 \%$ Confidence Interval } \\
\cline { 3 - 5 } & & & Lower Bound & Upper Bound \\
\hline Part Time & $43.781^{\text {a }}$ & 3.212 & 37.303 & 50.260 \\
Full Time & $23.156^{\mathrm{a}}$ & 2.950 & 17.207 & 29.106 \\
\hline \multicolumn{2}{l}{ a. Covariates appearing in the model are evaluated at the following values: Pretest $=15.10}$.
\end{tabular}


The results displayed in Table 9, showed that there was a significant interaction between the types of feedback and the modes of teaching on the posttest $(\mathrm{F}(2,43)=8.95, \mathrm{p}=.001$, partial $\mu 2=.294$ representing a large effect size $)$.

Testing the second research question

The second research question asked if the types of feedback, i.e. explicit written vs. explicit oral and the modes of teaching, i.e. part time vs. full time, have any effect on Omani students' retention of the passive voice in the delayed posttest. A two-way ANCOVA was run. Before discussing the results, it should be noted that the groups enjoyed homogenous variances on the delayed posttest $(\mathrm{F}(5,44)=.962, \mathrm{p}=.451)$.

Based on the results displayed in Table $13(\mathrm{~F}(2,44)=10.29, \mathrm{p}=.000$, partial $\mu 2=.319$ representing a large effect size), it can be claimed that there were significant differences between the three groups' mean values on the delayed posttest.

TABLE 13.

TESTS OF BETWEEN-SUBJECTS EFFECTS; DELAYED POSTTEST BY TREATMENTS BY MODES OF TEACHING

\begin{tabular}{|c|c|c|c|c|c|c|}
\hline Source & Type III Sum of Squares & Df & Mean Square & $\mathrm{F}$ & Sig. & Partial Eta Squared \\
\hline Treatment & 3335.939 & 2 & 1667.969 & 10.291 & .000 & .319 \\
\hline Mode & 2261.422 & 1 & 2261.422 & 13.952 & .001 & .241 \\
\hline Treatment $*$ Mode & 2386.128 & 2 & 1193.064 & 7.361 & .002 & .251 \\
\hline Error & 7131.746 & 44 & 162.085 & & & \\
\hline Total & 46800.000 & 50 & & & & \\
\hline
\end{tabular}

Table 14 displays the descriptive statistics for oral, written and control groups on the delayed posttest. The written group $(M=35.27)$ had the highest mean on the delayed posttest, followed by the oral $(M=23.33)$ and the control $(\mathrm{M}=$ 15.59) groups.

TABLE 14.

DESCRIPTIVE STATISTICS; DELAYED POSTTEST BY TREATMENTS WITH PRETEST

\begin{tabular}{lllll}
\hline \multirow{2}{*}{ Treatment } & \multirow{2}{*}{ Mean } & \multirow{2}{*}{ Std. Error } & \multicolumn{2}{l}{$95 \%$ Confidence Interval } \\
\cline { 3 - 5 } Control & & & Lower Bound & Upper Bound \\
Oral & 23.595 & 3.208 & 9.130 & 22.060 \\
Written & 35.278 & 3.208 & 16.868 & 29.799 \\
\hline
\end{tabular}

The results of the post-hoc comparison (Table 15) tests indicated that explicit written group $(\mathrm{M}=35.27)$ significantly outperformed the control group $(\mathrm{M}=15.59 ; \mathrm{MD}=19.97, \mathrm{p}=.000)$ on the delayed posttest; that there was not any significant difference between the explicit oral $(\mathrm{M}=23.33)$ and control $(\mathrm{M}=15.59)$ groups' mean values on the delayed posttest $(\mathrm{MD}=7.81, \mathrm{p}=.233)$ and that the written group $(\mathrm{M}=35.27)$ significantly outperformed the oral group $(\mathrm{M}=23.33)$ on the delayed posttest $(\mathrm{MD}=12.15, \mathrm{p}=.029)$.

TABLE 15.

PAIRWISE COMPARISONS; DELAYED POSTTEST BY TREATMENTS WITH PRETEST

\begin{tabular}{|c|c|c|c|c|c|c|}
\hline \multirow[b]{2}{*}{ (I) Treatment } & \multirow[b]{2}{*}{ (J) Treatment } & \multirow{2}{*}{ Mean Difference (I-J) } & \multirow{2}{*}{ Std. Error } & \multirow{2}{*}{ Sig. } & \multicolumn{2}{|c|}{ 95\% Confidence Interval for Difference } \\
\hline & & & & & Lower Bound & Upper Bound \\
\hline \multirow{2}{*}{ Written } & Control & $19.97 *$ & 4.374 & .000 & 8.88 & 31.05 \\
\hline & Oral & $12.15 *$ & 4.374 & .029 & 1.07 & 23.24 \\
\hline Oral & Control & 7.81 & 4.501 & .233 & -3.59 & 19.22 \\
\hline
\end{tabular}

*. The mean difference is significant at the .05 level.

Based on the results displayed in Table 13 above and Table 16 below, $(\mathrm{F}(1,44)=13.95, \mathrm{p}=.001$, partial $\mu 2=.241$ representing a large effect size), it can be claimed that the part time group $(\mathrm{M}=31.50)$ had a significantly higher mean than the full time group $(\mathrm{M}=17.96)$ on the delayed posttest.

TABLE 16.

DESCRIPTIVE STATISTICS; DELAYED POSTTEST BY MODES OF TEACHING WITH PRETEST

\begin{tabular}{lllll}
\hline \multirow{2}{*}{ Mode } & \multirow{2}{*}{ Mean } & \multirow{2}{*}{ Std. Error } & \multicolumn{2}{l}{ 95\% Confidence Interval } \\
\cline { 4 - 5 } & & & Lower Bound & Upper Bound \\
\hline Part Time & 31.508 & 2.673 & 26.120 & 36.896 \\
Full Time & 17.963 & 2.450 & 13.025 & 22.901 \\
\hline
\end{tabular}

\section{DISCUSSION}

The first research question asked if the types of feedback, i.e. explicit written vs. explicit oral and the modes of teaching, i.e. part time vs. full time, had any differential effect on Omani College students' accurate use of the passive voice in the posttest. The results indicated that both explicit written and explicit oral CF did have significant effects on Omani College students' accurate use of the passive voice in the posttest. However, no significant difference was found between the effects of explicit written and explicit oral on the students' accurate use of the passive voice. This may mean that explicit written and explicit oral have been equally effective. 
With respect to the modes of teaching (part time vs. full time), they were found to be differentially effective in the sense that part time students had a significantly higher mean value than that of the full time students in the post test meaning further that part time students benefitted more from the feedback provided than the full time students in using the passive voice accurately.

The second research question asked if the types of feedback, i.e. explicit written vs. explicit oral and the modes of teaching, i.e. part time vs. full time, had any differential effect on Omani students' retention of the passive voice. The results indicated that while explicit written CF did have a significant effect on Omani students' retention of the passive voice, explicit oral CF did not. In other words, there was no significant difference between the effect of explicit oral $\mathrm{CF}$ and the control group. In addition, a significant difference was found between explicit written $\mathrm{CF}$ and explicit oral $\mathrm{CF}$ on the students' retention of the passive voice in the delayed posttest meaning that explicit written was found to be more effective on the students' performance. Finally, With respect to the modes of teaching (part time vs. full time), they were found to be differentially effective in the sense that part time students were found to have benefitted more from the feedback provided compared to the full time students.

Based on the post test results, three differences can be identified. The first difference is between the experimental groups' pretest and their posttest performances which is significant as both groups' pretest scores and their posttest scores are significantly different from each other showing improvement from the pretest to the posttest while this is not the case in the control groups. The second difference is between explicit written and explicit oral groups' performances on the posttest which is NOT significant. The third difference is between part-time vs. full-time students' performance on the posttest which is significant. This shows that students in part-time vs. full-time have not benefitted from the given feedback in the same way as part time students did benefit more from the feedback given. There may be reasons for the differences observed.

Similarly, and based on the delayed posttest results, a couple of differences can be identified. The first difference is between explicit written and explicit oral on the one hand and explicit written and control group on the other. In other words, while explicit written CF group seem to have been significantly affected by the feedback provided, explicit oral group does not as explicit oral group did not perform better than the control group who did not receive any feedback. This may mean that participants in explicit oral group may have forgotten the feedback they received two session ago. Their performance was no different from that of the control group.

There might be reasons for the difference pointed out. Regarding the difference between the experimental groups on the one hand and the control groups on the other, feedback can be the reason as to why they performed better than the control groups in the posttest. In other words, the fact that feedback was explicit rather than implicit can explain why experimental groups outperformed the control groups. The difference can be attributed to the explicit feedback effect and the input enhancement effect they may have had leading to the experimental groups' better performance given that similar difference has already been observed by other researchers. For example, Bitchner and Knoch (2008) found out explicit feedback did assist learners clarify the points for themselves by making the presented learning input salient thereby helping them remove any possible doubts or misunderstandings of the input. Likewise, they pointed out that explicit feedback did assist learners to notice issues including grammar thereby helping them on their hypothesis making and testing. Finally, as Scrivener's (2005) points out, explicit feedback can be the fastest, and most helpful type of help that each and every student may be provided with. Though in this case written explicit seem to have worked better in the delayed posttest if not in the posttest. Finally, Caroll's (2001) views may be noteworthy here to note that explicit feedback can be more effective than implicit feedback. However, the aforementioned result is not in line with what Ellis et al (2013, p.363) proposed that "the advice given to teachers is to try to elicit self-correction from the learners rather than to correct them directly and explicitly."

With respect to part-time and full-time students' difference, there can be a number of explanations. The first reason can be attributed to the students' study behaviour. While full-time students had not been employed before attending their class, part-time students had been employed. The reason as to why part-time students attended evening classes was that they were busy with their jobs in the morning and they had no option but to attend their evening classes. Furthermore, and based on their class attendance record, part-time students did have better class attendance despite being busier with their work during the day. Besides, they showed more motivation to get involved in class activities. Finally, part-time students were seeking carrier promotion in addition to their higher education degree.

The second reason can be attributed to nature of the part-time and full-time students' classes. While part time students do attend from 5:00 to 8:30 in the evening, they are given a 20 minutes break after 110 minutes of teaching. This is not the case with full time students who attend their class in the morning and a break of 24 to 36 hours is given before they attend their second session of the week. This 20 minutes vs. 24/36 hours break difference might explain the reason as to why full-time and part-time students performed differently. Another reason is that full-time students may have been preoccupied with other modules so that they may have forgotten about the feedback they were provided with. The third reason can be attributed to the fact that part-time groups and full-time groups did not have the same teachers. Although for the sake of consistency, the researcher did attend both part-time and full-time classes and administered the tests, marked the tests and provided them with the required feedback, full-time students may not have taken the feedback they received as seriously as they did in the part-time groups wo were sitting in the researcher's class as the regular students. 


\section{CONCLUSION}

To conclude, and based on the results, it may not be too unrealistic to say that explicit written and explicit oral CF are both effective in raising the students' awareness to write correctly in their subsequent writing. Although there was no significant difference between the two types of feedback in the posttest, there was a significant difference between the two in the delayed posttest showing that explicit written could last longer due to the nature of the medium. In other words, while both types of feedback have been effective, explicit written feedback has been more effective in the delayed posttest. This may have been due to the possibility that explicit oral feedback may have had less lasting and more ephemeral effect. In other words, those receiving oral feedback, because of poor listening skills, may have been suffered and poor listening skills may have been responsible for the participants' performance in the post test and in the delayed posttest in that their feedback experience has been affected negatively. Indeed, some kind of initial comprehension check could have been given indicating that the feedback had actually been registered. Like any other study, this study has some limitations. The first limitation is the nature of the sampling which was convenience sampling. The second limitation could be the type of treatment provided which was based on the errors participants had made while answering the pretest items. This can be addressed in future studies where random sampling and writing samples can be employed.

\section{REFERENCES}

[1] Algaravi, B. S. (2010). The effects of repair techniques on L2 learning as a product and as a process: A CA-for-SLA investigation of classroom interaction, Thesis submitted for the degree of Doctor of Philosophy Integrated PhD in Educational and Applied Linguistics, Newcastle University School of Education, Communication and Language Sciences.

[2] Aljaafreh, A. \& J.P. Lantolf. (1994). Negative feedback as regulation: second language learning in the zone of proximal development. The Modern Language Journal, 78.4, 465-83.

[3] Ashwell, T. (2000). Patterns of teacher response to student writing in a multi-draft composition classroom: Is content feedback followed by form feedback the best method? Journal of Second Language Writing, 9.3, 227-257.

[4] Bitchener, J., \& U. Knoch. (2008). The value of written corrective feedback for migrant and international students. Language Teaching Research 12.3, 409-431.

[5] Bitchener, J., \& U. Knoch. (2009). The value of a focused approach to written corrective feedback, ELT Journal, 63.3, $204-213$.

[6] Chandler, J. (2003). The efficacy of various kinds of error feedback for improvement in the accuracy and fluency of L2 student writing. Journal of second language writing, 12.3, 267-296.

[7] Doughty, C. \& E. Varela. (1998). Communicative focus on form. In C. Doughty and J. Williams (eds.), Focus on form in classroom second language acquisition. Cambridge: Cambridge University Press, 114-138.

[8] Ellis, R. (2009). A typology of written corrective feedback types, ELT Journal, 63.2, 97-107.

[9] Ellis, R. (2009). Corrective feedback and teacher development, L2 Journal, 1.1, 3-18.

[10] Ellis, R., Sh. Loewen, \& R. Erlam. (2006). Implicit and explicit corrective feedback and the acquisition of L2 grammar. Studies in Second Language Acquisition, 28.3, 339-368.

[11] Erlam, R., R. Ellis, \& R. Batstone. (2013). Oral corrective feedback on L2 writing: Two approaches compared. System, 41.2, 257-268.

[12] Ferris, D., R. (1999). The case for grammar correction in L2 writing classes. A response to Truscott (1996). Journal of Second Language Writing, 8.1, 1-10.

[13] Ferris, D., R. (2003). Response to student writing: Implications for second language students. Mahwah, NJ: Lawrence Erlbaum.

[14] Ferris, R., D. (2008). Feedback: issues and options in P. Friedrich, Teaching academic writing. New York: Continuum.

[15] Ferris, D. R., \& B. Roberts. (2001). Error feedback in L2 writing classes: How explicit does it need to be? Journal of Second Language Writing, 10.3, 161-184.

[16] Ferris, D., R., S. J. Chaney, K. Komura, B., J. Roberts, \& S. McKee. (2000). Perspectives, problems, and practices in treating written error. In Colloquium presented at International TESOL Convention, Vancouver, B.C..

[17] Ferris, D., R., \& M. Helt. (2000). Was Truscott right? New evidence on the effects of error correction in L2 writing classes. Paper presented at Proceedings of the American Association of Applied Linguistics Conference, Vancouver, B.C..

[18] Hattie, J. \& H. Timperley. (2007). The power of feedback. Review of Educational Research 77.1, 81-112.

[19] Hyland, K., \& F. Hyland. (2006). Feedback on second language students' writing. Language Teaching.39.2, 83-101.

[20] Li, S. (2014). Oral corrective feedback. ELT Journal, 68.2, 196-198.

[21] Lei, L \& D. Liu. (2018). Research trends in applied linguistics from 2005 to 2016: A bibliometric analysis and its implications, Applied Linguistics, 1-23.

[22] Krashen, S., D. (1982). Principles and Practice in Second Language Acquisition. Oxford: Oxford University Press.

[23] Laland J. F. (1982). Reducing composition errors: an experiment. The Modern language Journal, 66.2, 140-149.

[24] Long, M. H. (1996). The role of linguistic environment in second language acquisition. In W. Ritchie and T. K. Bhatia (Eds.), Handbook of second language acquisition, 413-468. San Diego: Academic Press.

[25] Mackey, A. (1999). Input, interaction, and second language development. An Empirical Study of Question Formation in ESL. Studies in Second Language Acquisition, 21, 557-587.

[26] Lochtman. K. (2002). Oral corrective feedback in the foreign language classroom: how it affects interaction in analytic foreign language teaching. International Journal of Educational Research 37.3, 271-283.

[27] Lopez, M., S., S \& S., R., M. Manchon. (2010). The differential effect of two types of direct written corrective feedback on noticing and uptake: reformulation vs. error correction International Journal of English Studies, 10.1, 131-154.

[28] Lyster, R. \& L. Ranta. (1997). Corrective feedback and learner uptake: Negotiation of form in communicative classrooms, Studies in Second Language Acquisition 19.1,37-66. 
[29] Lyster R. \& K. Saito. (2010). Oral feedback in classroom SLA: A Meta-Analysis. Studies in Second Language Acquisition, $32.2,265-302$.

[30] Lyster, R., K. Saito, \& M. Sato. (2013). Oral corrective feedback in second language classrooms. Lang Teach. 46.1, 1-4.

[31] Nassaji H. (2009). Effects of recasts and elicitations in dyadic interaction and the role of feedback explicitness. Language Learning, 59.2, 411-452.

[32] Nassaji, H. \& M. Swain. (2000). A Vygotskyan perspective on corrective feedback in L2: The effect of random versus negotiated help in the learning of English articles. Language Awareness 9.1, 34-51.

[33] Polio, C. (2003). Research on Second language writing: An overview of what we investigate and how. In B. Kroll (ed.) Exploring the dynamics of second language writing, Cambridge: Cambridge University Press, 35-66.

[34] Ranta, L. \& R. Lyster. (2007). A cognitive approach to improving immersion students' oral language abilities: The AwarenessPractice-Feedback sequence. In R. DeKeyser (ed.), Practice in a second language: Perspectives from applied linguistics and cognitive psychology. Cambridge: Cambridge University Press, 141-160.

[35] Rassaei, E. (2013). Corrective feedback, learners' perceptions, and second language development, System 41.2, 472- 483.

[36] Rassaie, E. (2015). Oral corrective feedback, foreign language anxiety and L2 development, System 49, 98-109. https://doi.org/10.1016/j.system.2015.01.002 [accessed 11/9/2018].

[37] Rassaie, E. (2017). Tailoring mediation to learners' ZPD: effects of dynamic and nondynamic corrective feedback on L2 development, The Language Learning Journal. https://doi.org/10.1080/09571736.2017.1343863 [accessed7/9/2018].

[38] Semke, H. (1984). The effects of the red pen. Foreign Language Annals 17.3, 195-202.

[39] Robb, T., S. Ross, \& Shortreed I. (1986). 'Salience of feedback on error and its effect on EFL writing quality'. TESOL Quarterly 20.1, 83-93.

[40] Scrivener, J. (2005). Learning Teaching: A guidebook for English language teachers. Oxford: Macmillan Education.

[41] Sheen, Y. (2007). The effect of focused written corrective feedback and language aptitude on ESL learners' acquisition of articles, TESOL Quarterly, 41.2, 255-283.

[42] Sheen, Y. (2010). The role of oral and written corrective feedback in SLA, Studies in second language acquisition, 32.2, 169179.

[43] Sheen, Y. (2010). Differential effects of oral and written corrective feedback in the ESL classroom, Studies in second language acquisition, 32.2, 203-234.

[44] Sobhani, M. \& Tayebipour, F. (2015). The effects of oral vs. written corrective feedback on Iranian EFL learners' essay writing. Theory and Practice in Language Studies, 5.8, 1601-1611.

[45] Storch, N. (2010). Critical feedback on written corrective feedback research. International Journal of English studies, 10.2, 2946.

[46] Truscott, J. (1996). The case against grammar correction in L2 writing classes, Language learning, 46.2, 327-369.

[47] Truscott, J. (1999). The case for "The Case against Grammar Correction in L2 Writing Classes": A response to Ferris". Journal of second language writing. 8.2, 111-122.

[48] Vahdani Sanavi, R., \& Nemati, M. (2014). The effect of six different corrective feedback strategies on Iranian English language learners' IELTS writing task 2.Sage open.

[49] Yang, Y. \& Lyster, R. (2010). Effects of form focused practice and feedback on Chinese EFL learners' acquisition of regular and irregular past tense forms. Studies in Second Language Acquisition, 32.2, 235- 263.

Farhad Tayebipour was born in Shiraz, Iran. He earned his BA and MA degrees in TEFL (Teaching English as a Foreign Language) at Esfahan University in 1990 and 1995 respectively and his Ph. D degree in Applied Linguistics at Allameh Tabatabae'i University, Tehran, in 2012. He taught service and major English courses at Islamic Azad University, Shiraz Branch, to undergraduate and postgraduate students from 2000 to 2014. He joined Majan University College in Oman in September 2014. His areas of interest are Second Language Acquisition, L2 Pragmatics, Corrective Feedback, and L2 dynamic assessment.

Dr. Tayebipour has presented a number of papers in International conferences and has published papers in refereed Journals such as Journal of Language Teaching Skills, Applied Research on English Language and Theory and Practice in Language Studies. He has also published book chapters in books such as Asian Englishes: Changing Perspective in a Globalized World (2012) edited by Lawrence Jun Zhang, Rani Rubdy and Lubna Alsagoff, published by PEARSON and Language Assessment in the Middle East and North Africa: Theory, Practice and Future Trends (2017) edited by Christine Coombe, Peter Davidson, Atta Gebril, Deena Boraie, and Sahbi Hidri, published by TESOL Arabia. 